\title{
Harizko elektrohigadura bidezko ebaketa-prozesuko aldagaien azterketa altuera aldakorreko piezak ebakitzeko
}

\author{
Wire-EDM variable analysis for cutting parts \\ with workpiece-height variation
}

\author{
Aintzane Conde*1, Jose Antonio Sanchez ${ }^{2}$, Soraya Plaza ${ }^{3}$, Jun Wang ${ }^{4}$ \\ 1 Machine-Tool Institute (IMH) \\ ${ }^{2}$ Center for Advanced Aeronautic Manufacturing (CFAA) \\ 3 Faculty of Engineering of Bilbao (UPV/EHU) \\ 4 Tianjin University of Science \& Technology (TUST)
}

LABURPENA: Harizko elektrohigadura bidezko ebaketa-prozesua (WEDM) ezinbestekoa da gaur egun, industriak gainazal-akaberen eta dimentsio-perdoien inguruan eskatzen dituen fabrikazio-eskakizun zorrotzak betetzeko. Prozesuari buruzko ezagutzarekin batera softwarearen garapena integratzen duen ingurune batetik abiatuta, makina adimendunaren funtzionamenduaren helburua lortu ahal izango da; hots, makinak bakarrik, fidagarritasunez eta doitasunik galdu gabe funtzionatzea. Baina, horretarako, arazo larrien konponketak optimizatu behar dira; esate baterako, altuera aldakorreko piezak ebakitzeko arazoa. Lan honetan, altuera aldatzen den guneetan ebaketa-prozesuaren aldagairik esanguratsuenen portaera aztertzeko aukera ematen duen industria-sistema bat garatu da. Hau da, aurrea hartu ahal izango zaie arrazoi horrengatik gerta daitezkeen aldaketei, eta, horri esker, haria apurtzea edo prozesuaren harroketa-tasa txikitzea eragin dezaketen ezegonkortasun-arazoak saihestuko dira; hau da, produktibitateak behera egitea eragotz daiteke.

HITZ GAKOAK: WEDM, aldagaien azterketa, doitasuna.

\begin{abstract}
Wire Electro-Discharge Machining process (WEDM) has become essential to achieve the strict manufacturing demands required by industry, such as surface finish or dimensional tolerances. The knowledge of the process is the basis to reach the goal of the intelligent machine, this is, to work reliably and without losing precision without human interaction. For example, the problem of cutting workpieces with variable heights is one of the problems that must be take into account. In this work, an industrial system has been developed to analyze the behavior of most significant variables during the cutting process. That is to say, they can be anticipated for changes that may occur due to this reason, which will prevent the breakdown of the wire or the instability problems that may cause a reduction in the process rate.
\end{abstract}

KEYWORDS: WEDM, variables, analysis, precision.

* Harremanetan jartzeko / Corresponding author: Aintzane Conde Fernández, Machine Tool Institute (IMH), Azkue Auzoa 1, Postal Code 48, 20870 Elgoibar, Euskal Herria. - aintzane@imh.eus - https://orcid.org/0000-0003-3662-9524.

Nola aipatu / How to cite: Conde, Aintzane; Sanchez, Jose Antonio; Plaza, Soraya; Wang, Jun (2019). «Harizko elektrohigadura bidezko ebaketa-prozesuko aldagaien azterketa altuera aldakorreko piezak ebakitzeko»; Ekaia, ale berezia 2019, 45-55. (https://doi.org/10.1387/ekaia.19934).

Jasoa: 12 ekaina, 2018; Onartua: 26 uztaila, 2018.

ISSN 0214-9001 - eISSN 2444-3255 / (c) 2019 UPV/EHU

cc)(-)(2) Obra hau Creative Commons Atribución 4.0 Internacional-en

BY NC SA lizentziapean dago 


\section{ARTEAREN EGOERA}

Harizko elektrohigadura bidezko prozesuak (WEDM) sektore aeronautikoaren interesa piztu du azken urteotan, zimurtasun txikiaren ondorioz lor daitezkeen perdoi doituei esker. Izan ere, zenbait ikertzailek haren aldeko apustua egin dute firtree motako geometria konplexuak sortzeko brotxaketa-prozesua ordeztu baitezake [1-2].

Industriak gero eta premia zorrotzagoak ditu eta, beraz, gainazal-akabera eta dimentsio-perdoi horiek lortzeko, beharrezkoa da prozesuaren oso kontrol doitua izatea. Hori dela eta, oso baliagarriak dira azken urteetako garapen konputazionalak, gaur egun komunikazioaren sektorean datu-kopuru handia aztertzeko aukera ematen dutenak [3]. Orobat, prozesuaren izaera estokastikoak ere tresna horiek prozesu hori hobeto ulertzeko aukerarik onena direla pentsatzera bultzatzen du.

Hala ere, makina-erremintaren sektorean eta, batez ere, elektrohigaduraprozesuan, ez dira gehiegi erabiltzen. Horrenbestez, erabiltzen hasi aurretik, beharrezkoa da prozesuan parte hartzen duten aldagaiak aztertzea eta ebaketa-prozesuan eraginkorrenak zein diren jakitea. Eta, hain zuzen ere, prozesuan dauden aldagaien kopuru handia hura menderatzeko arazoetako bat da. Aldagai horiek prozesuaren baldintzekin lotuta dauden zenbait alderdi alda ditzakete, hala nola gainazal-akabera eta harroketa-tasa; alegia, prozesuaren errendimendua [4-5].

Azken urteotan, WEDM bidezko ebaketa-prozesuari buruzko argitalpenek doikuntzaren hobekuntzan jarri dute arreta, alde batetik, eta beste batetik, prozesuaren kontrolean eta monitorizazioan. Doitasunari dagokionez, prozesuaren egonkortasunari edo aldagaien hautaketa egokiari buruzko hainbat argitalpen daude (tradizionalki, aldagaiak esperimentu bidez hautatu dira, ezegonkortasunak saihestuz) [6-7], besteak beste gainazal-akabera edo harroketa-tasa hobeak lortzeko. Dena den, gero eta ohikoagoa da, horretarako, esperimentuen diseinua erabiltzea [8-11]. Bigarrenari dagokionez, deskargen karakterizazioa eta pieza-altueraren detekzioa dira landutako gaietako batzuk [12-13].

Gero eta potentzia handiagoko tresna konputazionalak erabiltzea funtsezkoa da hari bidezko ebaketan; izan ere, ezinbestekoak dira funtzionamendu fidagarria lortzeko, prozesuaren ezegonkortasunak gutxitzeko eta, etorkizunean, makina bakarrik funtzionatzen uzteko. Adibide gisa, zenbait egilek kontrol moldatzaile bat erabiltzen dute ebaketa-abiadura handitzeko [14]; beste batzuek beste alderdi batzuk jorratu dituzte, esate baterako, tentsioa eta intentsitatea denbora errealean monitorizatzeko sistemen garapena [15], eta ebaketa-prozesuan sortutako deskarga moten online sailkapena [16].

Lehenago azaldu denez, ebaketa-parametroak piezaren altuera bakoitzerako zehaztu behar dira; hori dela eta, lodiera aldakorreko piezen azterketa in- 
teres handiko gaia da. Hala, bi kasu bereizi behar dira: altuera handitzea, eta, hortaz, ebaketa-abiadura eta deskarga-dentsitatea txikitzea; eta altuera txikitzea, eta, beraz, ebaketa-abiadura eta deskarga-dentsitatea handitzea. Bigarren kasu horretan sortzen dira arazo gehien, haria apurtzeko arriskua baitago. Hain zuzen ere, kasu horietan aplikatu dira arazo hori konpontzen saiatzeko sare neuronalak erabiltzen dituzten lanak [11] edo denbora errealean kontrolatzeko edo monitorizatzeko teknikak [12-13], parametroak une oro ebakitzen den altuerara egokitzeko. Hala eta guztiz ere, kontrol eta egokitzapen horiek behar bezala egiteko sistema bat lortzeko, oinarrizkoa daaldagaien azterketa. Gainera, lan korapilatsua da edozein teknika industria-mailan ezartzea.

Hortaz, lan honetan azaldutako artearen egoera kontuan hartuta, prozesuan parte hartzen duten aldagaien azterketa sakona egitea proposatzen da, deskargen energia-edukia piezen dimentsio-perdoiekin erlazionatuko duen industria-sistema bat sortzeko. Sistema hori, beraz, altuera-aldaketa barnean hartzeko lehen pausoa da. Sistema prozesu bereko beste arazo batzuk aztertu ahal izateko aldez aurretiko pauso bat da.

\section{PROZEDURA}

Ebaketa-aldagaien ezaugarriak zehazteko, ebaketak egin dira altuera konstanteko piezetan $(100 \mathrm{~mm}, 80 \mathrm{~mm}, 60 \mathrm{~mm}, 40 \mathrm{~mm}$ eta $20 \mathrm{~mm})$ eta altuera aldakorreko piezetan $(100 \mathrm{~mm}-40 \mathrm{~mm}, 100 \mathrm{~mm}-60 \mathrm{~mm}$ eta $50 \mathrm{~mm}-30 \mathrm{~mm}$, ikus 1. irudiko $a$ eta $b$ balioak), 1. taulan ikusten denez. Lehenengo $4 \mathrm{~mm}$-ak ez dira kontuan hartuko, dielektrikoaren presioa oraindik ez baita egonkortu. Entsegu horiek bost aldiz egin dira, errepikakortasuna ziurtazteko asmoz. Harizko elektrohigadurako makina batean, ONA AX3 modeloan, egin dira, eta latoizko (CuZn37), 0,25 mm-ko diametroko hari bat erabili da, haustearen kontrako $900 \mathrm{~N} / \mathrm{mm}^{2}$-ko erresistentziakoa eta hausturarekiko \% 1eko elongaziokoa. Erabilitako piezaren materiala AISI D2 altzairua izan da, WEDMn ohikoa, erremintak eta tresnak egiteko erabiltzen dena. Karbonoa, kromoa, molibdenoa eta vanadioa duenez, altzairu horrek higaduraren kontrako erresistentzia aparta du, eta tenplaketarako eta iraoketarako propietate onak.

1. taula. Erabilitako parametroak piezaren altueraren arabera (lehenengo lerroan adierazita).

\begin{tabular}{lrrrrrr}
\hline & $100 \mathrm{~mm}$ & $80 \mathrm{~mm}$ & $60 \mathrm{~mm}$ & $50 \mathrm{~mm}$ & $40 \mathrm{~mm}$ & $20 \mathrm{~mm}$ \\
\hline Etenaldi denbora [ $\mu \mathrm{s}$ ] & 13,0 & 12,0 & 11,0 & 10,0 & 9,0 & 11,0 \\
Intentsitatea [A] & 5,0 & 5,0 & 5,0 & 5,0 & 5,0 & 5,0 \\
Zirkuitu irekiaren tentsioa [V] & 80,0 & 80,0 & 80,0 & 80,0 & 80,0 & 80,0 \\
Dielektrikoaren presioa [-] & 31,0 & 31,0 & 25,0 & 25,0 & 31,0 & 25,0 \\
Hariaren tentsioa [-] & 18,0 & 18,0 & 18,0 & 18,0 & 18,0 & 18,0 \\
\hline
\end{tabular}




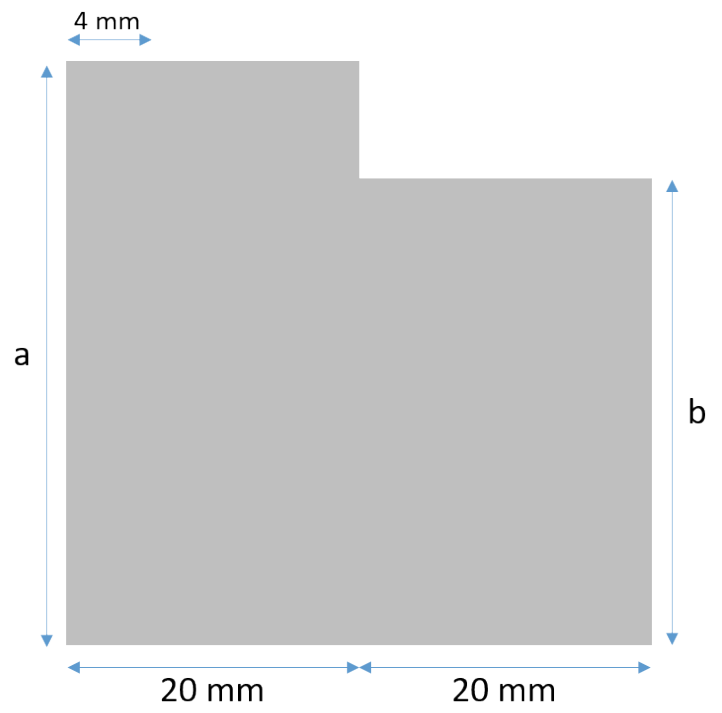

1. irudia. Aldagaien karakterizaziorako erabilitako probetak.

Erabili diren ebaketa-baldintzak 1. taulan ageri dira. Arbastu-prozesu batekoak dira, hots, energetikoena den prozesukoa. Orobat, ikus daitekeenez, fluido dielektrikoaren presioa ezin hobea da lodiera konstanteko ebaketetan (egindako entseguetan konstante mantentzen da ezarritako baliotik, aldaketak baztegarriak direla ikusita). Altuera aldatzen denean, berriz, presio txikiagoa erabiltzen duen teknologia erabiltzen da, piezaren geometria dela medio, eta horrek berekin dakar arteka okerrago garbitzen dela.

Egindako entseguetan, 4 mm-ko ebaketa linealak egin dira eremu egonkor batean altuera konstanteko piezetan, eta altuera aldakorrekoetan $2 \mathrm{~mm}$ aldaketa-gunearen aurretik, eta $2 \mathrm{~mm}$ ondoren. Makinaren datuak haren zenbakizko kontrolean instalatutako sistema baten bidez jaso dira. Datu horiek kanpoko memoria-gailu batean gorde dira, Matlab® softwarean diseinatutako aplikazio baten bidez aztertzeko. Aplikazio horretan, datu guztiak denborarekiko erlazioanadierazten dira. Aipatzekoa da lortutako datuek zarata-osagai bat dutela eta hura aplikazio horren bidez iragazi behar dela. Prozesuaren izaera estokastikoaren eta gerta daitezkeen ezegonkortasun txikien ondorio da zarata.

Aztertutako kasu guztietan ikusi denez, altuera handitik txikira bitarteko trantsizioetan sortzen dira bai ezegonkortasunak bai haria hausteko arriskua. Altuera txikitik handira bitarteko trantsizioetan, berriz, ebaketa-abiadura txikitu egiten da, eta, horren ondorioz, errendimenduak behera egiten $\mathrm{du}$; hori negatiboa da, baina ez hariaren haustura bezain larria. Ebaketarako 
beharrezkoa den deskarga-energia piezaren altuerarik handienerako ezartzen da, eta energia hori hariaren luzera osoan zehar banatzen da, baina energiak bere horretan jarraitzen du. Hori dela eta, onar dezakeena baino tentsio elektriko handiagoa izan dezake hariak, eta hautsi egin daiteke.

Altuera-aldaketa aztertzeko entseguetan lortutako aldagaiak bektoreetan gorde dira, eta bektore horiek 200.000 eta 400.000 bitarteko datu-luzera dute, aitzinamendu-abiaduraren eta laginketa-maiztasunaren arabera. Hainbeste datu aztertzea oso motela izan daitekeenez, haiek gutxitzea erabaki da, eta, erreferentzia-puntu gisa babes-etenaldien baliorik handiena hartu da (hori baita ezegonkortasunik handieneko puntua eta, beraz, piezaren altuera aldatzen den puntua).

\section{EMAITZEN ANALISIA}

Lehenago aipatu denez, entseguak bost aldiz egin dira pieza bakoitzean, emaitzen errepikagarritasuna egiaztatzeko; hots, kasu guztietan emaitzek joera bera dutela egiaztatzeko. Egiaztatu da azpiko aldagai hauek ematen dituztela emaitzarik aipagarrienak.

\subsection{Deskarga-motak}

Higadura-denborarekin erlazionatutako aldagaiek ebaketa-prozesuaren etapen iraupenari buruzko informazioa ematen dute (ionizazio-denbora - deskarga-denbora - etenaldi-denbora). Azpitalde horretan, aldagai hauek daude:

- Ionizazio-denbora $\left(\mathrm{t}_{\mathrm{d}}\right)$ : dielektrikoa ionizatzeko eta ebaketa-prozesuan deskargak mugituko diren arteka sortzeko beharrezko denbora-neurria da. Halaber, elektrodoaren eta piezaren arteko distantziari eta honen abiadurari buruzko informazioa ematen du.

- Pultsu-denbora: deskarga-periodoaren guztizko iraupena adierazten $\mathrm{du}$; hau da, bulkada-denboraren $\left(\mathrm{t}_{\mathrm{on}}\right)$ eta etenaldi-denboraren $\left(\mathrm{t}_{\mathrm{off}}\right)$ batura.

- Erreferentziazko serbo-tentsioa: fabrikatzaileak aurrez zehaztutako tentsioaren balioa da. Deskargak hasi aurretik, tentsioak erreferentzia horretatik gorako balio bat izango du, arteka ionizatzen hasteko. Behin ionizatuta dagoenean, tentsioa erreferentzia horretatik behera jaitsiko da, eta deskargak hasiko dira.

Deskargekin erlazionatutako aldagaiek une bakoitzean zenbat deskarga gertatzen diren adierazten dute eta deskargak ionizazio-denboraren arabera sailkatzen dituzte, deskargaren arteka sortzen ari den denbora-tartearen arabera, alegia. 2. irudian, deskarga baten eremu bereizgarriak ikusten dira, eta deskargaren ionizazio-denbora zehaztu daiteke. 


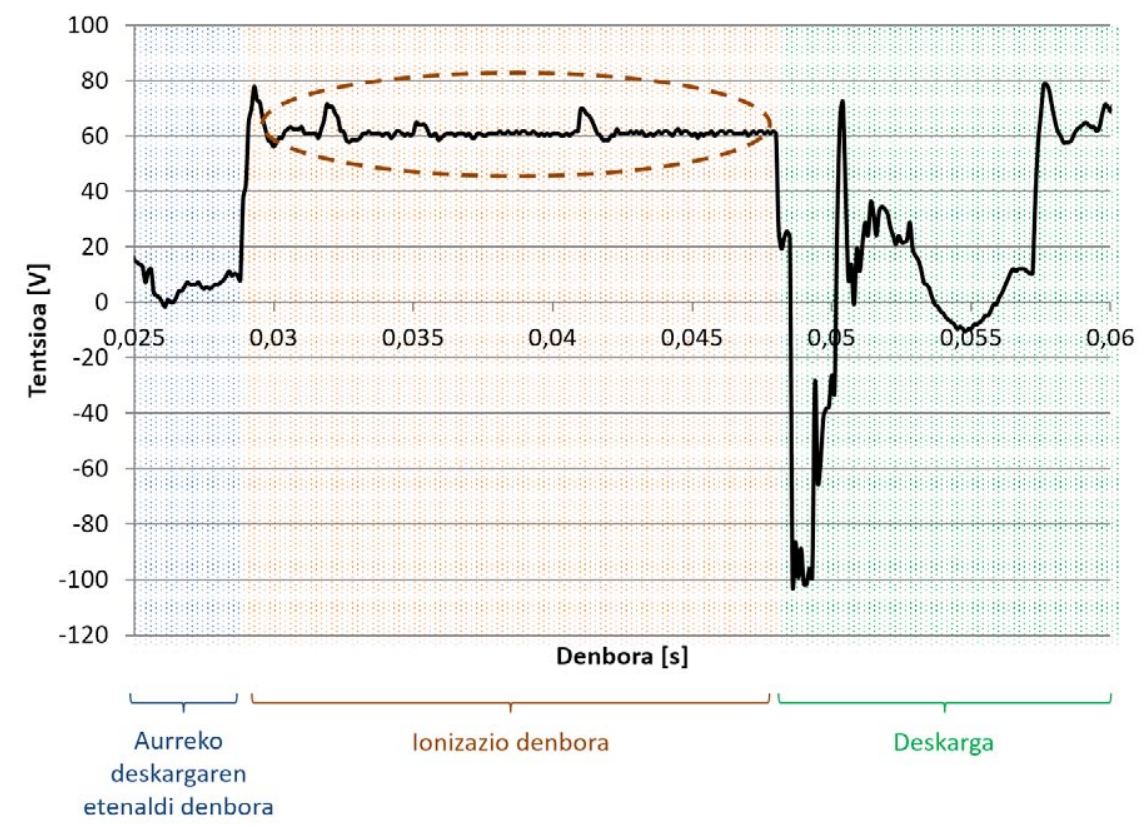

2. irudia. Deskarga baten etapak.

Orain, sistemak deskarga-motekin erlazionatuta jasotako aldagaiak deskribatuko dira:

- Guztizko deskargak: lagindutako denbora-tartean guztira gertatzen diren deskargak.

- D3, ionizazio-denbora luzeko deskargak: ebaketa-prozesuko garrantzitsuenak dira, piezaren materiala erauzten dutenak. Deskarga horiek $10 \mu$ s-tik gorako ionizazio-denbora behar dute.

- D1 eta D2, ionizazio-denbora ertaineko deskargak: guztizko deskargen eta gainerako deskargen kendura dira. Ebaketa-prozesuaren analisiari dagokionez, ez dute interes berezirik.

- Do, ionizazio-denbora laburreko deskargak: talde horretan, $3 \mu \mathrm{s}$-tik beherako ionizazio-denbora duten deskargak sartzen dira. Deskarga horiek ionizazio-denbora luzeko deskargek baino material gutxiago erauzten dute, baina, hala ere, deskargen guztizko kopuruan kontuan hartzekoak dira, prozesuaren gainerako aldagaiei eragiten baitiete.

- DOO, ionizazio-denbora nuluko deskargak.

Ionizazio-denbora da teknologiaren bidez ezartzen ez den aldagai bakarra. Alegia, gainerako aldagaien aldakortasunak balio teorikoarekiko edo erabiltzaileak ezarritako balioarekiko desbideratzeak adierazten du; dena 
den, ionizazio-denbora desberdina da deskarga bakoitzean. Lodiera konstanteko piezekin egindako entseguetatik ondoriozta daitekeenez, joera bera dago denetan, ehuneko 7 punturen aldakortasunarekin, piezaren lodieraren arabera. Deskargak ionizazio-denboraren arabera multzokatzen badira (2. taulan bezala), 3. irudia lor daiteke 10 entsegutarako.

2. taula. Deskarga-motak, ionizazio-denboraren arabera.

\begin{tabular}{lc}
\hline & Ionizazio-denbora $(\mathrm{td})$ \\
\hline D00 deskarga-mota & $\mathrm{td}=0 \mu \mathrm{s}$ \\
$D 0$ deskarga-mota & $0 \mu \mathrm{s}<\mathrm{td}<3 \mu \mathrm{s}$ \\
$D 1$ deskarga-mota & $3 \mu \mathrm{s}<\mathrm{td}<5 \mu \mathrm{s}$ \\
$D 2$ deskarga-mota & $5 \mu \mathrm{s}<\mathrm{td}<10 \mu \mathrm{s}$ \\
$D 3$ deskarga-mota & $10 \mu \mathrm{s}<\mathrm{td}$ \\
\hline
\end{tabular}

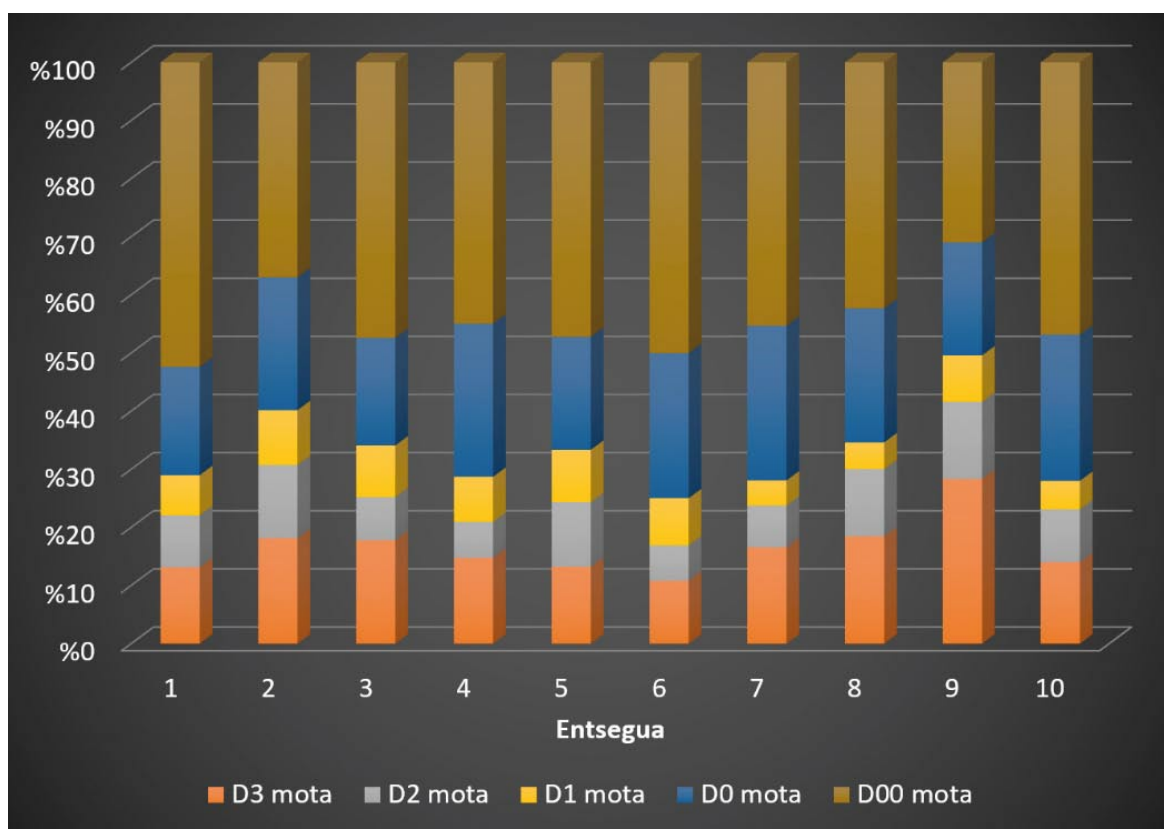

3. irudia. Ionizazio-denbora aldagaiaren emaitzak.

Lodiera aldakorreko piezekin egindako entseguei dagokienez, aldagai horren portaera ikusteko, ionizazio-denboraren indizea ezarri da: ionizazio-denboraren batez besteko balioa da, ehunekotan, $5 \mu \mathrm{s}$-ko eremu bakoitzerako. Lodiera aldatzen den eremuaren inguruan, indize horrek konstante izateari utzi, eta gora eta, gero, behera egiten du. Ondoren, konstante jarraitzen du aurrekoaz bestelako balio batean, 4. irudiko adibidean (lodiera 
$100 \mathrm{~mm}$-tik $80 \mathrm{~mm}$-ra txikitzen da) ikus daitekeenez. Hau da parametro hori aldatzeko arrazoia: lodiera handitzen denean, txikitu egiten da aitzinamenduaren kontrako erresistentzia, baita hariaren eta piezaren arteko distantzia ere, eta hori hariaren eta piezaren arteko distantziaren aldagaian islatzen da.

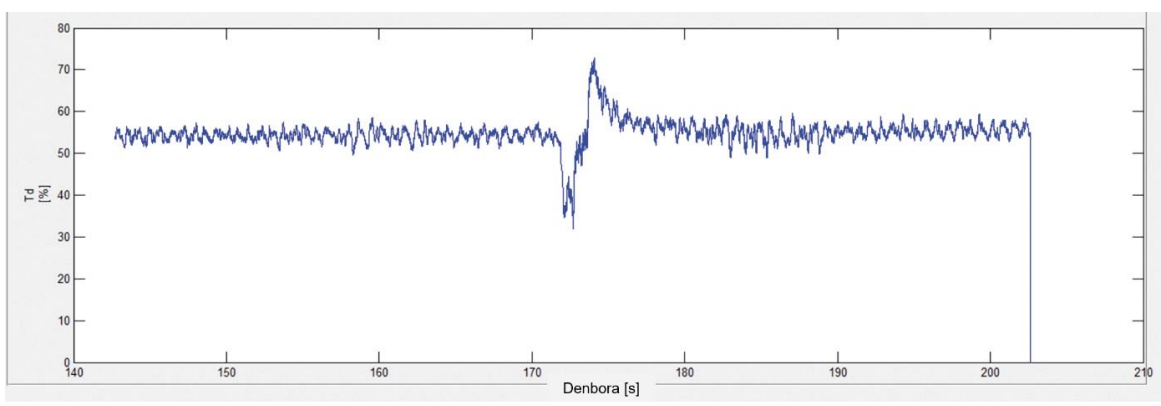

4. irudia. Ionizazio-denbora portzentaia altuera aldakorreko piezan.

\subsection{Gap-errorearen aldagaia}

Ionizazio-denboraren eta pultsu-denboraren arteko loturak ionizaziodenborak periodo baten guztizko iraupenean zer indize duen $\left(\mathrm{t}_{\mathrm{d}} \%\right)$ adierazten duenez, beste aldagai bat ezartzea erabaki da: gap-errorea. Ionizaziodenboraren indizearen eta erreferentziazko serbo-tentsioaren arteko aldea adierazten duen neurria da. Gap-errore positiboek adierazten dute ionizazio-denborak optimoa baino luzeagoak direla; kasu horretan, deskargarako denbora gutxiago dago, eta, hortaz, prozesuaren produktibitateak behera egiten du. Aitzitik, gap-errore negatiboek adierazten dute ionizazio-denborak laburregiak direla; kasu horretan, deskargaren arteka ezin da behar bezala sortu (ikus 5. irudia).

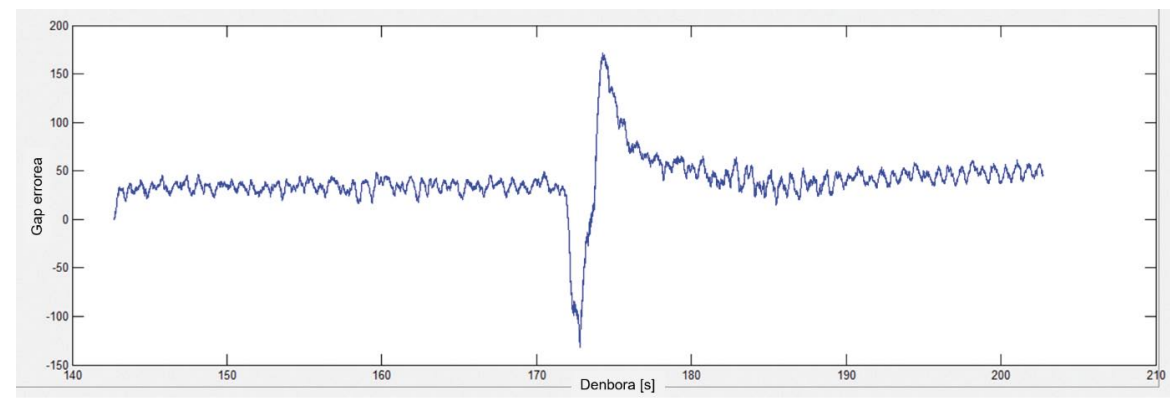

5. irudia. Gap-errorearen seinalearen adibidea. 


\subsection{Makinaren kotak}

Makinaren koten aldagaiaren bidez, ebaketa-prozesuan zehar haria $\mathrm{X}$ ardatzean zein $\mathrm{Y}$ ardatzean zer posiziotan dagoen jakin daiteke. Gainera, aldagai horietan jasotako puntuak erabiliz, kurba jarraitu bat egin eta deriba daiteke, abiadura lortzeko: abiadura ezagutzeko beste metodo bat da, prozesuaren beste barne-aldagairik behar ez duena.

Abiaduraren aldagai berria eta ebaketa-prozesuan lortu behar diren abiadura teorikoak kontuan hartuta, piezaren lodiera off-line kalkula daiteke. Industria-sistemak aldagaiaren balioa datu-base batekin alderatu eta balio horri dagokion lodiera ondorioztatzen du. Altuera konstanteko eremuan, abiadura altuera horren mende dagoen balio baten ingurukoa da. Altuera aldatzen denean, abiadura bat-batean handitzen da oso denbora-tarte laburrean; ondoren, aldagaia beste balio batean egonkortzen da.

Abiadura prozesuaren barne-aldagaietatik abiatuta kalkulatu nahi bada ere, aipatutako pauso hori beharrezkoa da garatutako sistemak behar bezala funtzionatzen duela egiaztatzeko.

Gaur egun, seinaleen maiztasun-azterketa egiten da, alde batetik, zarata desagerrarazteko, eta, bestetik, iragazpena egiteko modu eraginkorragoak aurkitzeko. Maiztasun-azterketa aprobetxatuz, lodiera-aldaketako eremuan maiztasun nagusirik dagoen azter daiteke, eta, horri esker, informazio gehiago lor daiteke gertatzen ari diren ezegonkortasunei buruz.

\section{ONDORIOAK}

Industriak gero eta interes handiagoa du lodiera aldakorreko piezak ebakitzean doitasuna hobetzeko, eta hori izan da, hain zuzen, lan honen abiapuntua. Horretarako, lehenik eta behin, prozesuaren barne-aldagaiak ingurune bizkor, malgu eta adiskidetsu batean jasotzeko eta adierazteko modua proposatu da.

Egindako lanaren ondorioak honako hauek dira:

- Beste industria-sistema bat garatu da, kalkulu teknikoko programazio-lengoaia batean oinarrituta, eta sistema horrek aukera eman du prozesuaren aldagaiek altuera-aldaketako eremuetan nolako portaera duten aztertzeko.

- Altuera-aldaketako eremuetatik hurbil eta haria hausten den kasuetan, ebaketa-baldintzak zehazten dituzten aldagaien joera aldatu egiten da.

- Ebaketa-prozesuaren aldagairik garrantzitsuenak sakon aztertu dira, lodiera-aldaketa batean nola aldatzen diren egiaztatzeko; garrantzitsuenetako bat ionizazio-denbora da. 


\section{ESKER ONAK}

Lan hau Eusko Jaurlaritzaren Industria, Berrikuntza, Merkataritza eta Turismo Sailak «Balio erantsi handiko osagaiak fabrikatzeko EDM aplikazio berriak» ikerketa-proiektuaren (S-PE12UN093) bidez emandako laguntzari esker egin ahal izan da. Orobat, eskerrik asko ONA Electroerosión SAri, ikerketan emandako laguntzagatik.

\section{BIBLIOGRAFIA}

[1] Klocke F., Welling D., Klink A., Veselovac D., Nöthe T., Perez R.: Evaluation of Advanced Wire-EDM Capabilities for the Manufacture of Fir Tree Slots in Inconel 718. Procedia CIRP 14 (2014) 430-435.

[2] Ayesta I., Izquierdo B., Flaño O., Sánchez J.A., Albizuri J., Avilés R. Influence of the WEDM process on the fatigue behavior of Inconel@ 718. International Journal of Fatigue, 92-1(2016) 220-233.

[3] Krizhevsky A., Sutskever I., Hinton G. E.: ImageNet classification with deep convolutional neural networks. Proceedings NIPS, 25 (2012) 1106-1114.

[4] Sen R., Choudhuri B., Deb Barma J., Chakraborti P.: Optimization of wire EDM parameters using teaching learning based algorithm during machining of maraging steel 300. Materials Today: Proceedings, 5-2 (2018) 7541-7551.

[5] Ugrasen G., Ravindra H. V., Naveen Prakash G.V., Theertha Prasa, Y. N.: Optimization of Process Parameters in Wire EDM of HCHCr Material Using Taguchi's Technique. Materials Today: Proceedings, 2 4-5 (2015) 24432452.

[6] Liao Y.S., Yan M.T., Chang C.C.: A neural network approach for the on-line estimation of workpiece height in WEDM, J. Mater. Process. Technol., 121 (2002), 252-258.

[7] Alekseyev G.A., Korenblum M.V.: Analysis of the Conditions for the High Efficiency Wire Cut EDM, Proceedings of the Ninth International Symposium for Electro-Machining (ISEM-9), Nagoya, Japonia, (1989).

[8] Liao Y.S., Huang J.T., Su H.C.: A study on the machining parameters optimization of wire electrical discharge machining, J. Mater. Process. Technol., 71:3 (1997), 487-493.

[9] Huang J.T., Liao Y.S.: Optimization of machining parameters of wire-EDM based on grey relational and statistical analyses, Inter. J. Prod. Res., 41:8 (2003), 1707-1720.

[10] Gokler M.I., Ozanozgu A.M.: Experimental investigation of effects of cutting parameters on surface roughness in the WEDM process, Inter. J. Mach. Tools Manuf., 40:13 (2000), 1831-1848.

[11] Tosun N., Cogun C., Inan A.: The effect of cutting parameters on workpiece surface roughness in wire EDM, Machining Sci. Technol., 7:2 (2003), 209219. 
[12] Caggiano A., Teti R., Perez R., Xirouchakis P.: Wire EDM Monitoring for Zero-defect Manufacturing based on Advanced Sensor Signal Processing. Procedia CIRP, 33 (2015) 315-320.

[13] Guangwei H., Weiwen X., Wansheng Z.: Online workpiece height estimation for reciprocated travelig wire EDM based on support vector machine. Procedia CIRP, 68 (2018) 126-131.Sato T., Morita Y. Adaptive control technology for wire-cut EDM, Mitsubishi Electrical Corporation R\&D Progress Report (2002).

[14] Portillo E., Cabanes I., Marcos M., Sánchez J.A.: Supervisión de la degradación del proceso de electroerosión por hilo, Proc. MESIC, Madril (Espainia), (2007).

[15] Liao Y.S., Cheng M.P., Liao K.W.: An on-line pulse trains analysis system of the wire-EDM process, J. Mat. Proc. Tech., 209:9 (2009), 4417.

[16] Liao Y.S., Yan M.T., Chang C.C.: A neural network approach for the online estimation of workpiece heigh in WEDM, Journal of Materials Processing Technology, 121 (2002), 252-258.

[17] Rajurkar K.P., Wang W.M., Zhao W.S.: WEDM-adaptive control with a multiple input model for identification of workpiece height, University of Nebraska, Lincoln, USA (1997).

[18] Liao Y.S., Chuang T.J., Yu Y.P.: On-line workpiece height estimation and its application in servo feed control of WEDM process, Procedia CIRP, 6 (2013), 226-231. 